\title{
HIGH VELOCITY THERMAL GUN FOR SURFACE PREPARATION AND TREATMENT
}

\author{
I.A. Gorlach \\ Department of Industrial Engineering \\ School of Process and Mechanical Engineering \\ Technikon Witwatersrand \\ Johannesburg, South Africa \\ igorlach@twrinet.twr.ac.za
}

\begin{abstract}
Many surface preparation and treatment processes utilise compressed air to propel particles against surfaces in order to clean and treat them. The effectiveness of the processes depends on the velocity of the particles, which in turn depends on the pressure of the compressed air. This paper describes a thermal gun built on the principles of High Velocity Air Fuel (HVAF) and High Velocity Oxy Fuel (HVOF) processes. The designed apparatus can be used for abrasive blasting, coating of surfaces, cutting of rocks, removing rubber from mining equipment, cleaning of contaminations etc.
\end{abstract}




\section{Introduction}

Conventional sand/shot blasting methods use a stream of high velocity air to propel the sand or other abrasives against the surface to be cleaned and prepared for painting. Despite numerous developments in nozzle design the productivity of the conventional method is still mainly dependant on the pressure of the compressed air being used. Conventional sandblasting systems have reached their limit in terms of performance, mainly due to the difficulties of obtaining and maintaining the high pressure of compressed air. Figure 1 shows the diagram of the conventional abrasive blasting system.

The HVAF and HVOF processes have been successfully applied in metal spraying for a decade. Attempts were also made to use these processes for abrasive blasting. For example, the apparatus designed by J. Browning [1] and described in US Patent 5,283,985. The main disadvantages of the previous systems are their complexity in operating, the requirements of oxygen for combustion and water for cooling and bulky designs.

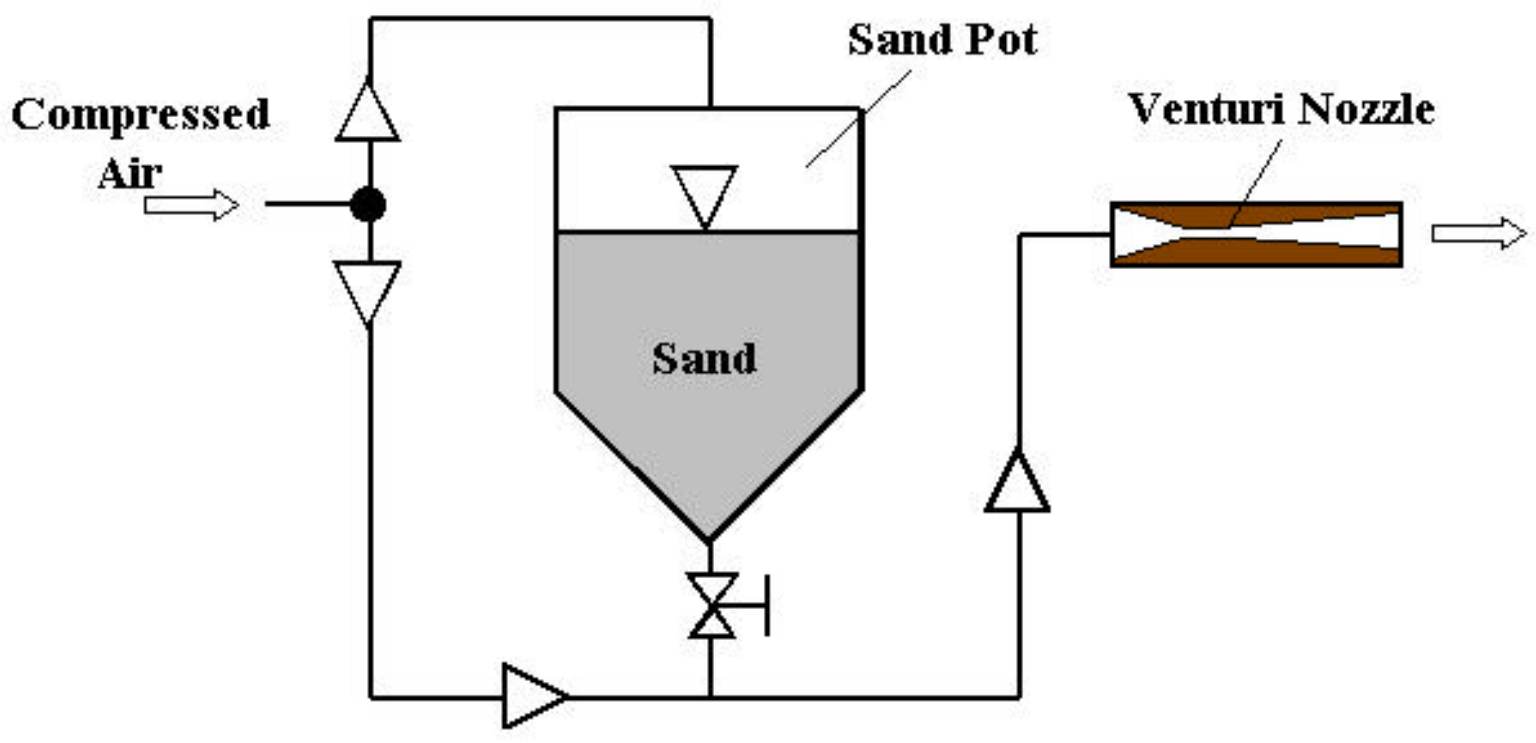

Figure 1. Diagram of the conventional abrasive blasting system

\section{Theoretical Basis}

The HVAF and HVOF processes use a high velocity flame-jet provided by combustion of a fuel, which releases heat and generates a high temperature pressurized gas. The gas is directed through a nozzle to form a high velocity flow stream. The particles are introduced in the high velocity flow stream and accelerated by it to a supersonic velocity. The obtained two-component supersonic high-temperature enthalpy jet possesses high kinetic energy, which can be converted into useful work. The particle velocity depends on pressure, nozzle parameters, particle size, shape and mass. Figure 2 shows the relationship between dynamic pressure and velocity of particles of 0,3 to $0,7 \mathrm{~mm}$ in diameter. 


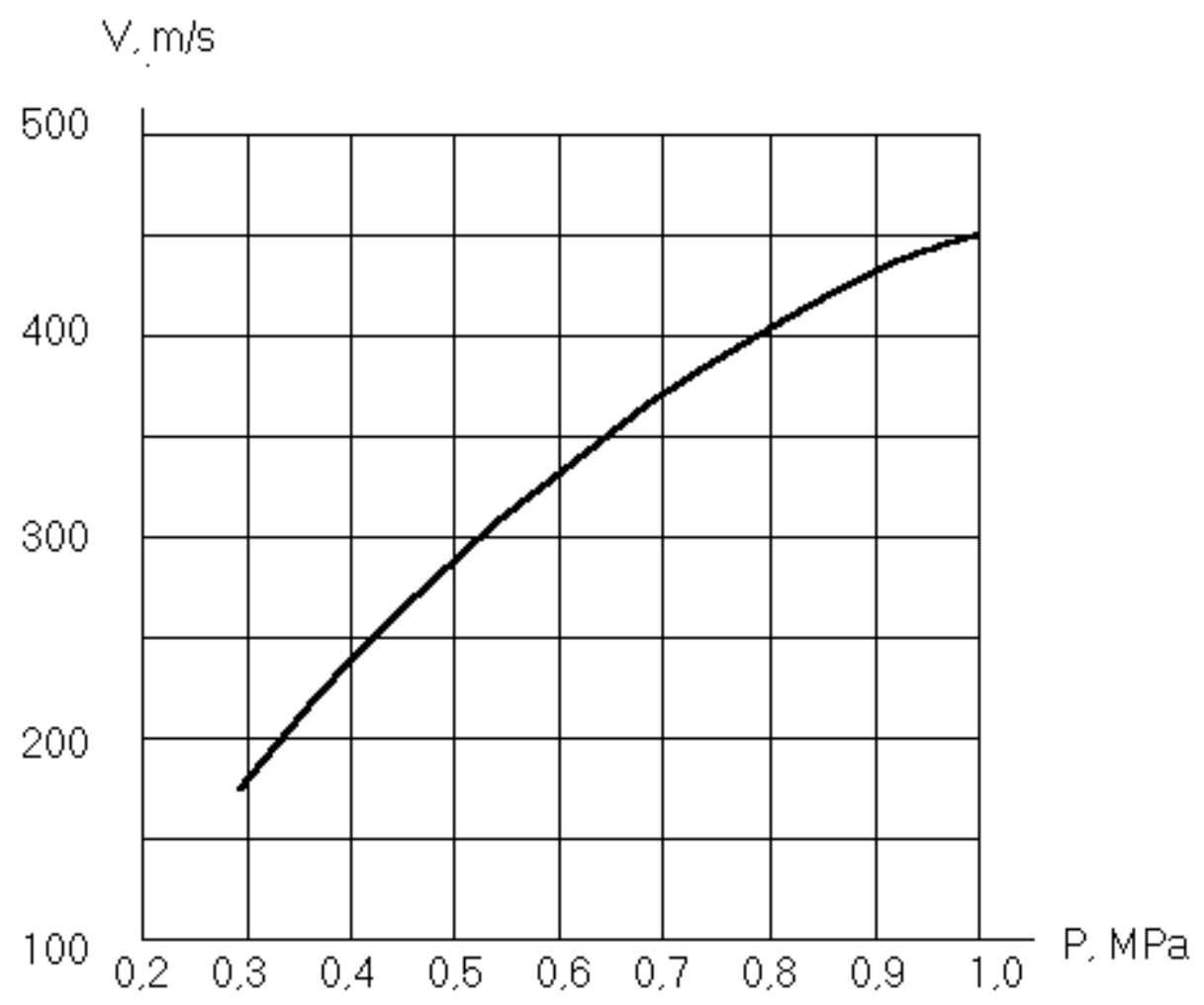

Figure 2. The relationship between pressure and particle velocity

A gas cycle of a high velocity thermal gun includes combustion and expansion in a nozzle. According to Cohen [2], the efficiency of a combustion process can be expressed as follows:

$$
\eta=\frac{\text { Theoretica } 1 \alpha \text { for given } ? \mathrm{~T}}{\text { Actual } \alpha \text { for given } \Delta \mathrm{T}}
$$

Where: $\alpha=$ the fuel/air ratio

$? \mathrm{~T}=$ the combustion temperature rise

The combustion temperature rise depends on the fuel/air ratio and gas properties. For common hydrocarbon fuels these values are given in the tables. For example, for paraffin, containing $13,92 \% \mathrm{H}$ and $86,08 \% \mathrm{C}$, with an initial temperature of $300 \mathrm{~K}$ and a combustion temperature rise of $900 \mathrm{~K}$, it requires a fuel/air ratio of 0.025 . The combustion efficiency is difficult to measure accurately. In practice combustion is nearly complete, therefore $\eta=95-99 \%$.

Referring to Figure 3, a converging nozzle is considered because it is adequate for calculation of thrust and velocity of gas flow in a critical area of a nozzle. The ultimate criteria of performance of a high velocity thermal gun is thrust, which is expressed as follows: 


$$
F=m\left(V_{c}-V_{l}\right)+A_{c}\left(P_{c}-P_{l}\right)
$$

Where: $\mathrm{m}=$ the mass flow, $\mathrm{g} / \mathrm{s}$

$\mathrm{V}=$ the velocity of flow, $\mathrm{m} / \mathrm{s}$

$\mathrm{P}=$ the pressure, $\mathrm{Pa}$

$\mathrm{A}_{c}=$ the area of a nozzle

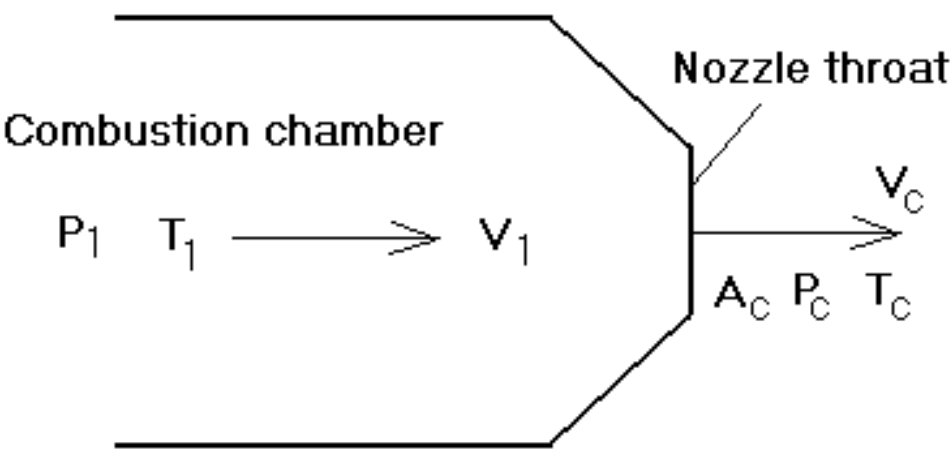

\section{Figure 3. Diagram of a nozzle system}

The critical pressure ratio is:

$$
\frac{P_{1}}{P_{c}}=\frac{1}{\left[1-\frac{1}{\eta}\left(\frac{\gamma-1}{\gamma+1}\right)\right]^{\gamma /(\gamma-1)}}
$$

Where: $\mathrm{P}_{1}=$ the pressure in the combustion chamber

$\mathrm{P}_{\mathrm{c}}=$ the pressure in the critical area of the nozzle, or a throat

$\gamma=$ the ratio of specific heats,

Ratios of specific heats are found from the graphs, depending on the temperature and the fuel/air ratio. For combustion gases $\gamma=1,333$.

Assuming the pressure in a combustion chamber is $\mathrm{P}_{1}=8$ bars and the combustion efficiency is $\eta=0.95$, then the critical ratio and pressure in the nozzle are:

$$
\begin{aligned}
& \frac{P_{1}}{P_{c}}=\frac{1}{\left[1-\frac{1}{\eta}\left(\frac{\gamma-1}{\gamma+1}\right)\right]^{\gamma /(\gamma-1)}}= \\
& =\frac{1}{\left[1-\frac{1}{0.95}\left(\frac{1.333-1}{1.333+1}\right)\right]^{1,333 /(1,333-1)}}=1,914
\end{aligned}
$$




$$
P_{c}=\frac{8}{1,914}=4,2 \text { bar }
$$

The emperature of the critical area of a nozzle is found from the ratio and the temperature in a combustion chamber as follows:

$$
T_{c}=\left(\frac{2}{\gamma+1}\right) T_{1}=\left(\frac{2}{1,333+1}\right) 200=1028 \mathrm{~K}
$$

The gas density in a nozzle is:

$$
\rho=\frac{P_{c}}{R T_{c}}=\frac{100 \times 4,2}{0,287 \times 1028}=1,425 \mathrm{~kg} / \mathrm{m}^{3}
$$

Where: $\mathrm{R}=$ the universal gas constant, (for combustion gas $\mathrm{R}=0,287$ )

The gas velocity in a nozzle is:

$$
V_{c}=\sqrt{\left(\gamma R T_{c}\right)}=\sqrt{(1,333 \times 0,287 \times 1028 \times 1000)}=627 \mathrm{~m} / \mathrm{s}
$$

The specific area of a nozzle, or area per mass flow, is determined as follows:

$$
A_{s}=\frac{A_{c}}{m}=\frac{1}{\rho \times V_{c}}=\frac{1}{1,425 \times 627}=0,0011 \mathrm{~m}^{2} \cdot \mathrm{s} / \mathrm{kg}
$$

Assuming the velocity of gas in a combustion chamber as $\mathrm{V}_{1}=140 \mathrm{~m} / \mathrm{s}$ and the pressure outside nozzle as 1 bar,(i.e. complete gas expansion), then the specific thrust is:

$$
F_{s}=\left(V_{c}-V_{1}\right)+\frac{A_{c}}{m}\left(P_{c}-P_{a}\right)=(627-140)+0,0011 \times(4,2-1) \times 10^{5}=839 \mathrm{~N} \cdot \mathrm{s} / \mathrm{kg}(10)
$$

Taking the mass flow $\mathrm{m}=0,12 \mathrm{~kg} / \mathrm{s}$ for the flow rate of a typical compressor the diameter of the critical area of a nozzle is determined using equation (9) as follows:

$$
\begin{aligned}
& A_{c}=m \times A_{s}=0,12 \times 0,0011=0,00013 \mathrm{~m}^{2} \\
& D_{c}=\sqrt{\frac{4 \times A_{c}}{\pi}}=\sqrt{\frac{4 \times 0,00013}{\pi}}=0,013 \mathrm{~m}=13 \mathrm{~mm}
\end{aligned}
$$

The full thrust using equation (10) is:

$$
\mathrm{F}=\mathrm{m} \times \mathrm{F}_{\mathrm{s}}=0,12 \times 839 \approx 100 \mathrm{~N}
$$


According to Glushko [3] the power of the thermal gun can also be limited by the operator's fatigue, therefore the diameter of the critical area of a nozzle can be expressed as follows:

$$
A_{c}=\frac{F}{C_{T} P_{1}}
$$

Where: $F=$ the thrust, $\mathrm{N}$

$P_{1}=$ the pressure in the combustion chamber, $\mathrm{Pa}$

$C_{T}=$ the thrust coefficient, which depends on the pressure, see Figure 4

For the above conditions this formula gives the same result.

$$
\begin{aligned}
& A_{c}=\frac{F}{C_{T} P_{1}}=\frac{100}{1 \times 0,8 \times 10^{5}}=0,000125 \mathrm{~m}^{2} \\
& D_{c}=\sqrt{\frac{4 \times A_{c}}{\pi}}=\sqrt{\frac{4 \times 0,000125}{\pi}}=0,0126 \mathrm{~m}=13 \mathrm{~mm}
\end{aligned}
$$

The entry diameter of the nozzles should be equal to the diameter of the combustion chamber. The exit diameter of the nozzle, $D_{\text {exit }}$, is calculated as follows:

$$
D_{\text {exit }}=\varphi \cdot D_{c}
$$

Where: $D_{c}=$ the critical diameter of nozzle, $\mathrm{mm}$

$\varphi=$ the flanging coefficient, which is determined from the graph, Figure 4

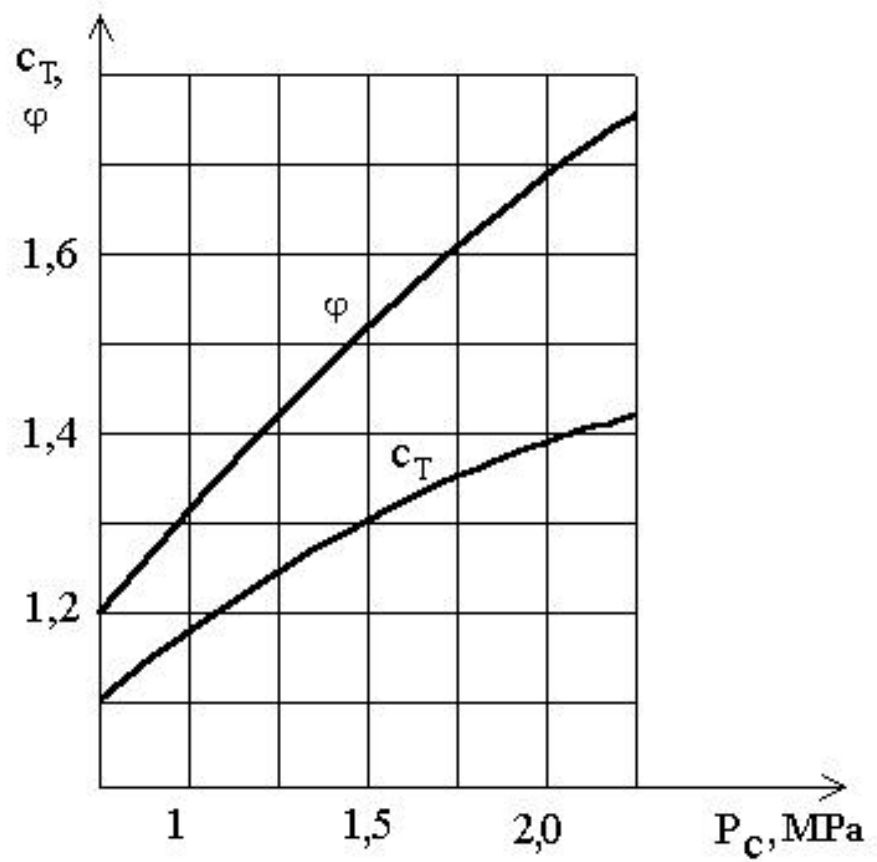

Figure 4. Thrust and flanging coefficients versus pressure 
In a simple term the ratio of the critical diameter of nozzle to the combustion chamber diameter determines the velocity of gas. The sustainable combustion process is achieved when this ratio is:

$$
\frac{D c}{D_{1}} \leq 0,2
$$

Where: $D_{l}=$ the diameter of a combustion chamber, $\mathrm{mm}$

It is recommended to choose the diameter of the combustion chamber $D_{l}$ as

$$
D_{1}=k_{d} \cdot D_{c}
$$

Where: $2,6 \leq \mathrm{k}_{\mathrm{d}} \leq 3$

The high velocity thermal gun utilises the regenerating cooling method where the oxidizer is also used for cooling. Referring to Figure 5, the thermal gun has three housings. The annular passages between them are chosen according to the flow rate of the compressed air, which is required for the combustion process. The wall thickness of the three housings should be between 1,5 and $4 \mathrm{~mm}$. The annular passages should be between 2 and $4 \mathrm{~mm}$. Reducing area of the annular passages intensifies the heat absorption due to increasing air velocity. However it increases resistance and results in a pressure drop.

The linear dimensions of the thermal gun depend on the size of the combustion chamber, which is divided into two sectors, an active zone and an after-burning zone. In the active zone the amount of oxidizer is gradually increasing to the fuel/air ration. The air is delivered into the combustion chamber in zones, a number of which can vary from 4 to 8 . Each zone has rows of holes. In order to provide stable increase of oxidizer the sums of areas of holes in each zone must be the same. The parameters of combustion process vary along the combustion zone. Hence the sizes of holes should vary, however it increases the manufacturing costs of combustion housings.

The linear dimensions of the combustion housing can be determined as follows:

$$
\begin{aligned}
& L_{a c}=k_{l} \cdot \frac{D_{c}}{D_{c o m}} \geq 100 \mathrm{~mm} \\
& L_{a f t e r}=k_{a} \cdot L_{a c}
\end{aligned}
$$

Where: $800 \leq \mathrm{k}_{1} \leq 900$

$$
0,75 \leq \mathrm{k}_{\mathrm{a}} \leq 10,75
$$

\section{The Design of the Thermal Gun}

Figure 5 shows the sectional view of a thermal gun. The sustainable performance of the system can only be achieved if the specific parameters of the process are obtained. 
Referring to Figure 5, fuel valve 6 has needle 8 . The primary goal of needle 8 is to regulate the amount of fuel delivered to the system. The needle has a cylindrical part and a tapered end. The cylindrical part provides an annular passage for the fuel, hence dispersing fuel. The gap between the tapered end and the delivery opening of fuel valve regulates the amount of fuel when needle 8 moves up and down.

$>$ The bottom of the fuel valve is positioned inside of the gun concentric with the radial hole of fuel injector 7 with gap D. The end of the fuel valve and the radial hole of fuel injector have chamfers, therefore creating an annular passage for the air. Gap D allows about $10 \%$ of the compressed air going into fuel injector to break the fuel into droplets. Thus providing a first stage of fuel/air mixing.

$>$ Fuel and air mix further in the annular passage $\mathrm{C}$, which is formed by the inner core of fuel injector 7 and nozzle 9. In the annular passage the second stage of fuel-air mixing takes place. The fuel/air mixture is, then, ejected through holes $\mathrm{F}$ of fuel injector 7, which are posistioned at an angle to the axis of the gun, into the combustion chamber G. Going though the holes the mixture is broken into small droplets of very high velocity.

The main steam of compressed air is directed first to an annular passage A. Then it goes through holes $\mathrm{B}$ in nozzle holder 4 and into an annular passage $\mathrm{H}$. A portion of this air enters combustion chamber $\mathrm{G}$ through the radial holes in combustion housing 3 . The rest of the air turns around and goes through spiral grooves $\mathrm{E}$ of fuel injector 7 into combustion chamber $\mathrm{G}$. The spiral grooves gives a swirling movement to the air. While going through an annular passage $\mathrm{H}$ the air becomes hot by absorbing the heat from the combustion housing 3 while cooling it.

The two streams, fuel/air mixture and hot swirled air, intersect with each other at the entrance of combustion chamber $G$ creating a turbulence. This is a final stage of fuelair mixing.

\section{b) Igniting of the mixture}

Ignition of the fuel/air mixture is achieved by means of an electric spark between two electrodes. An electronic ignition transformer provides a high voltage spark $(14 \mathrm{kV})$. The supply voltage of the transformer is $12 \mathrm{~V} \mathrm{DC}$ at 5 Amps that can be drawn from a car battery. The gun is started at low volumes of the fuel/air mixture. Once started the combustion process is self-sustained. While hot the thermal gun can be started at full flow. 


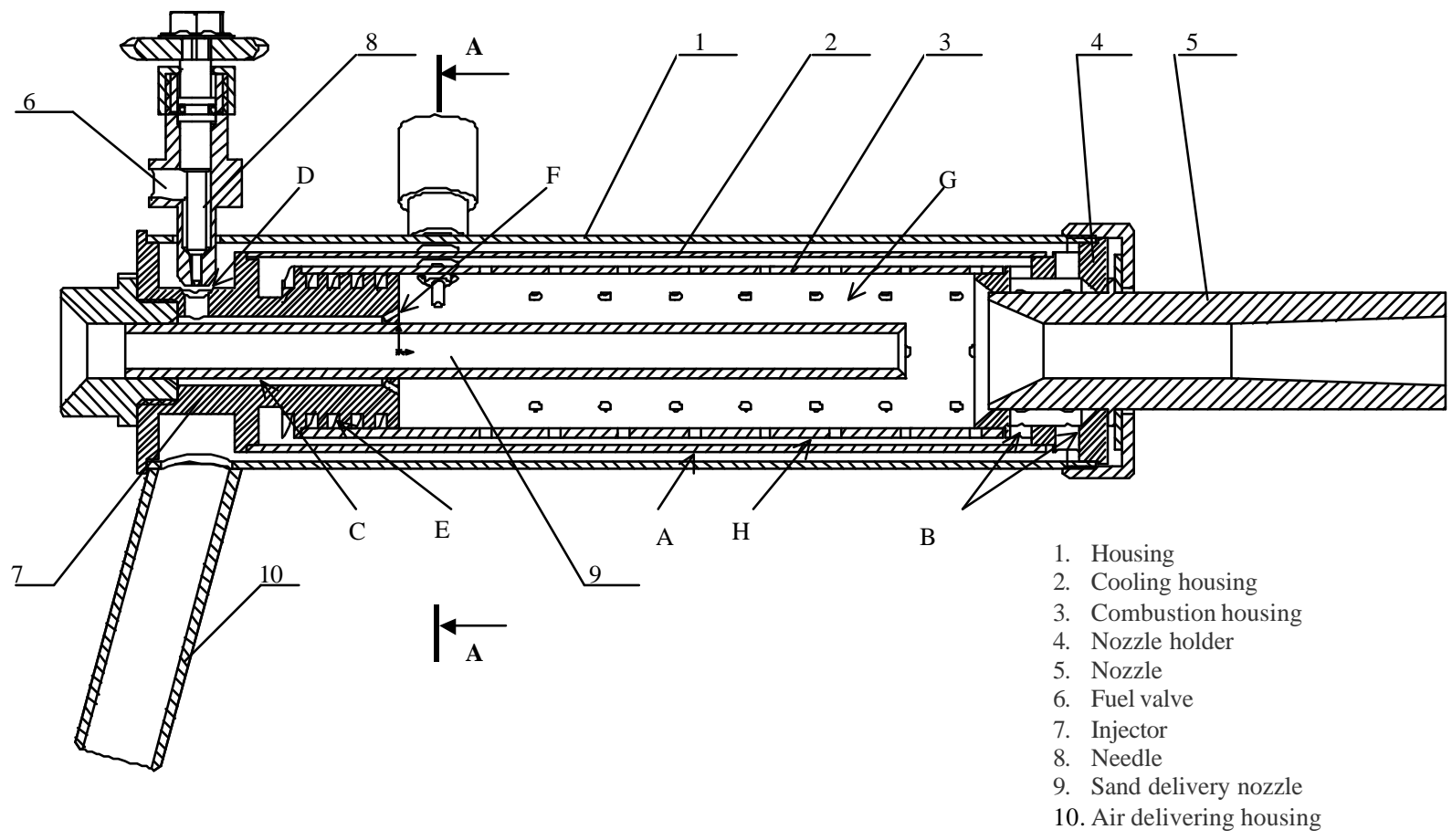

Figure 5. Design of a thermal gun

\section{c) Stabilising of the combustion process}

Combustion housing 3 has the rows of radial and tangential holes. These holes are important for various purposes. Firstly, they bring oxidizer in along a combustion zone providing a stable combustion process in varying conditions. Secondly, they bring in cold air, which protects combustion housing from overheating and subsequent collapsing. Thirdly, the radial holes help to hold a flame inside the combustion zone providing complete burning of a fuel. Lastly, the tangential holes add swirling to the fuel/air mixture, increasing atomising of the mixing and therefore improving the combustion process.

The stable performance of the system is achieved within the following design parameters:

1. A ratio of the cross-sectional area of the nozzle to the cross-sectional area of the combustion chamber is between 0,1 and 0,14 .

2. Annular passage A between housing 1 and cooling housing 2 is less than 0,8 of the cross-sectional area of pipe 10.

3. Annular passage $\mathrm{H}$ between cooling housing 2 and combustion housing 3 is between 2,5 and 3 of the cross-sectional area of the nozzle.

4. The sum of the areas of all air passages to combustion chamber is less than 2 times the cross-sectional area of the nozzle.

5. Compressed air for holding a flame inside of combustion chamber $G$ is to be introduced through combustion housing 3 in 6 rows of holes. The diameter of holes is between 4 and $6 \mathrm{~mm}$. 
6. Compressed air for cooling combustion housing 3 is to be introduced into combustion chamber $G$ through number of rows of holes. The diameter of holes is between 1 and $1,5 \mathrm{~mm}$.

\section{d) Delivery of abrasives}

The abrasive/air mixture is supplied axially through delivering nozzle 9 (Figure 5). The flow is then directed through a converging-diverging nozzle. The relationship between the nozzle geometry and particle velocity is shown in Figure 6. The nozzle design includes the cylindrical part, which increases the initial acceleration of flow. The final particle velocity depends on the length of the diverging part. The critical area diameter of the nozzle is determined as shown above. For example, for a combustion chamber $40 \mathrm{~mm}$ in diameter, the nozzle diameter is $14 \mathrm{~mm}$.

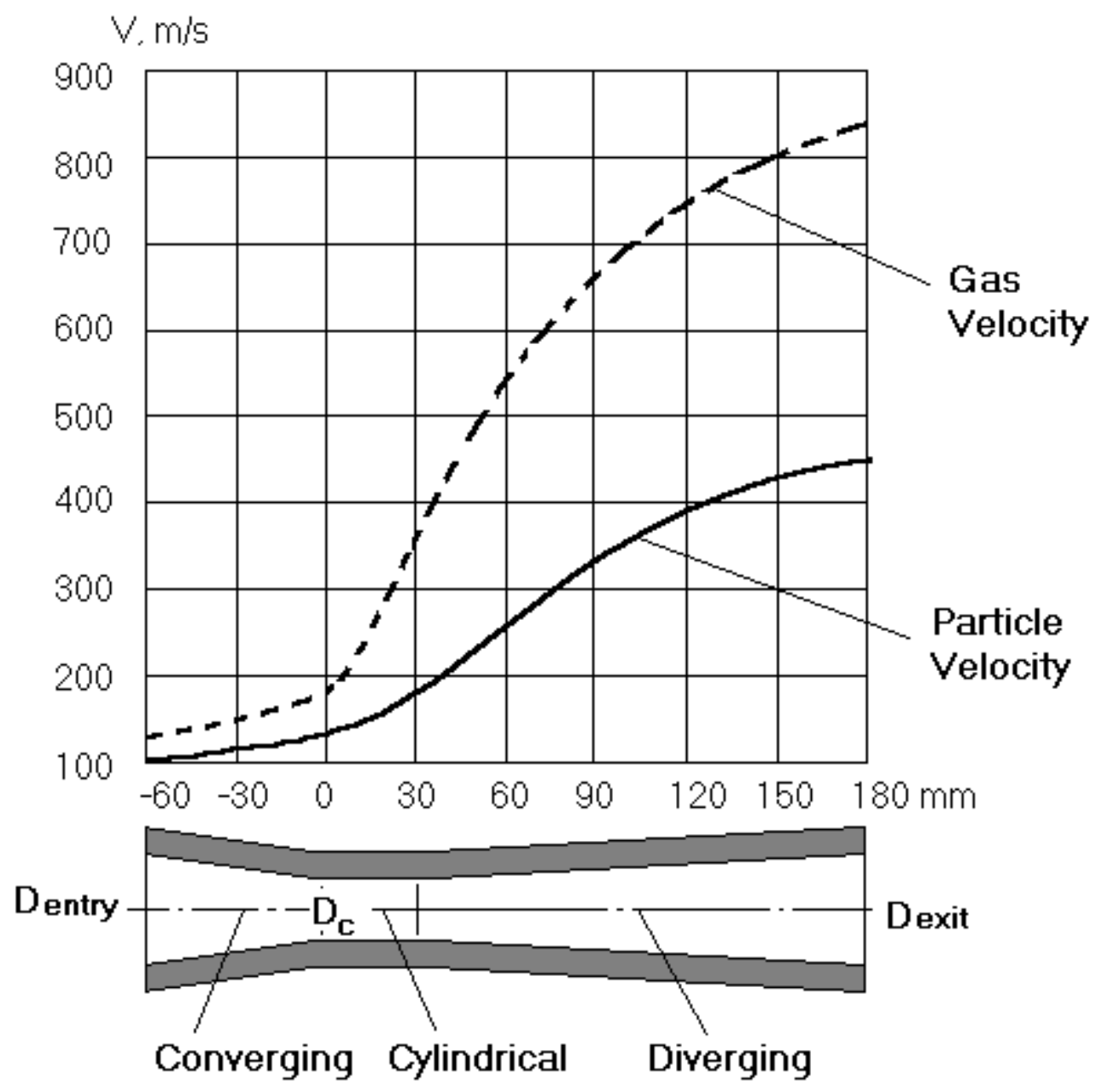

Figure 6. The relationship between the nozzle geometry and particle velocity

The blasting nozzle of the thermal gun is subjected to high mechanical stresses, extreme thermal stresses and wear. The nozzle temperature reaches $900^{\circ} \mathrm{C}$ in the diverging zone. The converging zone is cooled by the flow of compressed air (Figure 5). One of the ways of cooling the nozzle in the diverging zone is to use a suction effect of high velocity 
stream. Hence, no air from the system is wasted on cooling. Nozzles are subjected to high tensile, compression and hoop stresses. Nozzle toughness is also important from the handling point of view. Therefore nozzle materials must have good all-round mechanical properties.

The nozzle wear depends on particle material properties and their velocity. The most abrasive material used in sand blasting is $\mathrm{Al}_{2} \mathrm{O}_{3}$. Materials suited for nozzles are ceramics and cermets. For example, commonly used tungsten carbide has high toughness, tensile strength and thermal shock resistance. However, cobalt, which is a binder, tends to oxidize at high temperatures. Therefore intensive cooling is essential. Ceramics nozzles are made of boron nitride, silicon carbide and SIALON. The latter has excellent wear properties, good mechanical strength and thermal shock properties. However, a rapid change of temperature still poses problems for ceramics.

\section{A Comparison of the Systems}

The tests were performed on manufactured steel. The results are shown in Table 1. The blasting medium was platinum slag with particles size between 0,3 and $0,7 \mathrm{~mm}$. The fuel consumption of the thermal gun is between 5 and 7 liters per hour. As it can be seen from Table 1 the productivity of the thermal gun is three times higher. The direct operating costs are up to $50 \%$ less compared to conventional abrasive blasting.

\section{Table 1: Productivity Comparison}

\begin{tabular}{|l|c|c|}
\hline Parameters & Thermal Gun & Conventional Systems \\
\hline Pressure, bar & 5 & 5 \\
\hline Flow rate, cfm & 200 & 200 \\
\hline Cleaning Time, min & 1 & 3 \\
\hline Quantity of abrasives, $\mathrm{kg}$ & 8 & 25 \\
\hline Paraffin consumption, 1 & 0.1 & - \\
\hline
\end{tabular}

The thermal gun works in conjunction with conventional sand blasting equipment, such as mobile or stationary sand pots. Therefore there is no need to replace existing equipment. The only requirement is a slight modification of the hoses and fitting on the sand pot. The overall diagram of the system is shown in Figure 7. The recommended sizes of hoses are: 1 inch for the sand hose and $3 / 4$ inch for the air hose. 


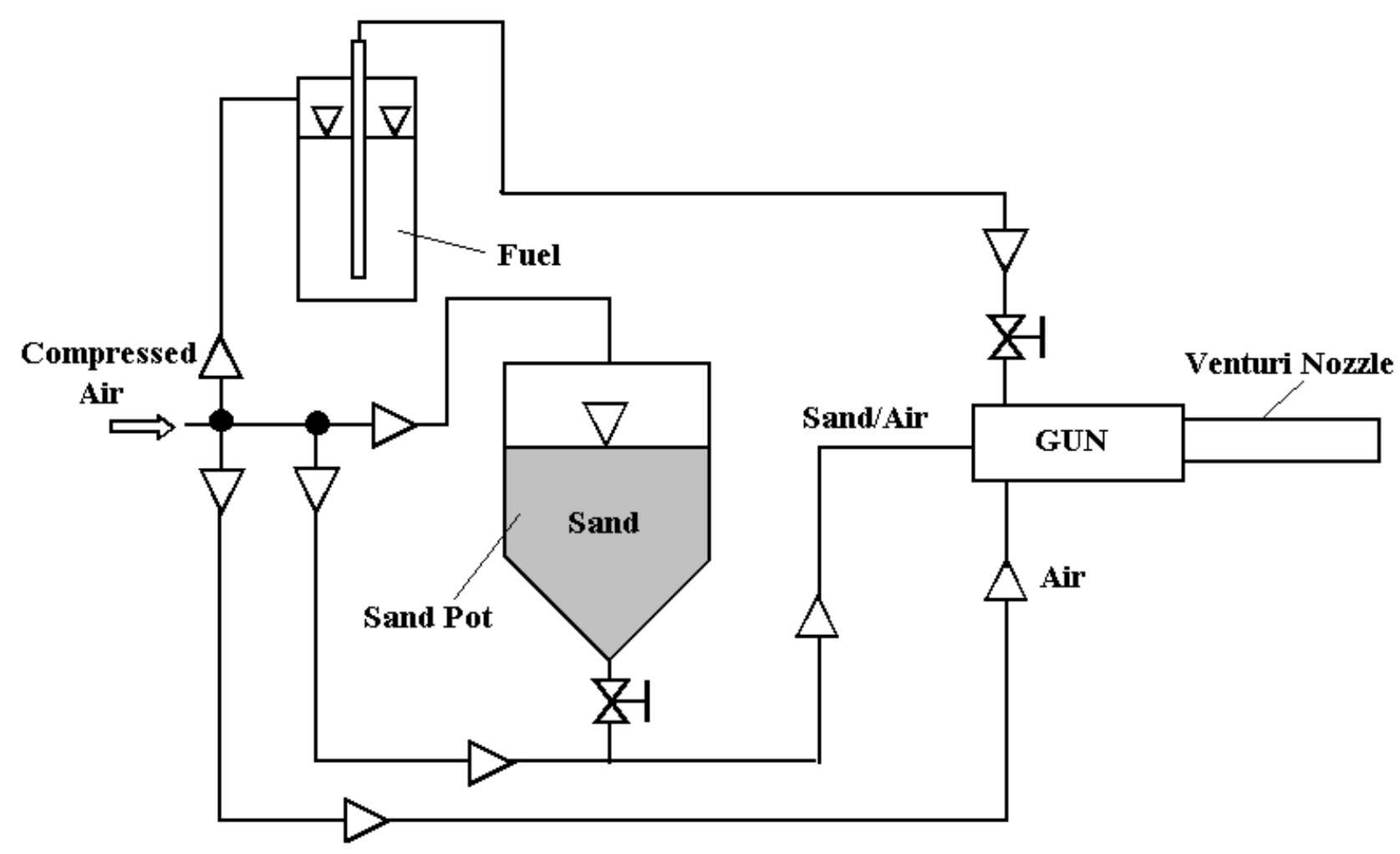

\section{Figure 7. Diagram of the thermal gun system}

\section{Conclusions}

The main advantages of the thermal gun include:

$>$ higher productivity

$>$ lower operating costs

$>$ the pressure is produced right at the blasting nozzle

$>$ lower consumption of blasting sand

$>$ heat removes moisture, oil and other impurities from blasted surfaces

$>$ the oil that comes from the compressor is burnt

$>$ surfaces are heated up, allowing painting processes in winter

$>$ better adhesion of paint

The HVAF and HVOF technologies offer great potential for surface preparation and treatment processes. Different systems can be developed for various industrial applications.

\section{References}

[1] Browning J., Extreme energy method for impacting abrasive particles against a surface to be treated, US Patent 5,283,985, 1994

[2] Cohen H. et al, Gas turbine theory, Cornwall, 1996 
[3] Glushko V. et al, Thermodynamic and thermo physical characteristics of fuels, Moscow. 1973

[4] Kaleberda V et al, Method of engineering calculations of generators of gaseous jets, Kharkov, 1982

[5] Sabadash V., Specifics of designing generators of gaseous jets, Kharkov, 1982 